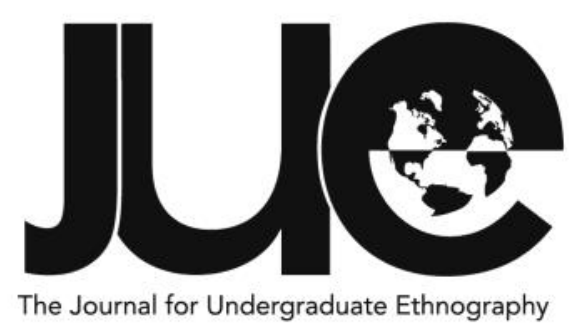

\title{
From Pedestrian Thoroughfare to Public Space: The Social Life of the Esplanade Underpass
}

Hoa Nguyen

Yale-NUS College, Singapore, hoaxn.nguyen@gmail.com

\section{ABSTRACT}

This study examines the Esplanade Underpass, an underground thoroughfare in Singapore that supports a range of public users and uses, despite not being a formally planned or officially designated public space. The Esplanade Underpass serves as an interesting case study as most public spaces in Singapore are zoned and governed by regulations of various kinds. The Esplanade Underpass, however, is minimally subject to these forms of surveillance and control. This research asks: What are the characteristics of the Esplanade Underpass that set it apart from the narrative of order and control often imposed upon public spaces in Singapore?" Through participant observation and interviews, the study investigates the users and uses of the Underpass. The study reveals how a range of users of the Underpass adapt the physical space for various uses, consequently establishing a series of informal social norms. Through varied habitual uses, the Underpass has been transformed from a place of transit into a meaningful public space which possesses a vibrant social life. The study highlights the nuances of social engagement that can work to make spaces "public" and offers a novel understanding of informally formed public space in Singapore.

Keywords: public space, sociospatial dynamics, Singapore, urban ethnography 
- he provision of public space is central to the planning and design of cities. In public space, the city's political and social dynamics manifest; the diverse elements of its inhabitants, history and culture come together. Under modern city planning regimes, the creation of spaces for the public has been accompanied by a stronger emphasis on order and control. In this context, public space often becomes overly planned and regulated, sterile and controlled. From this, a contradiction arises. On the one hand, officially designated public spaces have become less inclusive of the diverse profiles and interests of the wider public. On the other hand, spaces not originally intended for public usage have emerged as vibrant spaces with various actors and activities. The public spaces of Singapore are no exception to this contradictory trend.

Opened in 2002, the Esplanade Underpass is an underground pedestrian transit space that connects the downtown cultural complex of the Esplanade Theatres with nearby landmarks, commercial buildings and transport networks. Originally designed solely for pedestrian transit, the Esplanade Underpass now hosts a variety of unplanned functions, including informal roller blading, dancing and picnicking. In the highly regulated city-state of Singapore, such transformation is rare. While guidelines exist on the usage of the space in the form of signage prohibiting certain activities, management and monitoring are minimal. As its diverse users adapt the space for their various needs, the Esplanade Underpass gains new meanings beyond its originally designated function, and becomes a well-used and well-loved space.

Through a qualitative study of the Esplanade Underpass (hereafter "the Underpass"), the study asks: who are the users of the Esplanade Underpass, and why do they come to this space? What are the factors that lead to the use of the Esplanade Underpass as a leisure space? How do the users of the Esplanade Underpass interact with the space, and with one another? This research draws upon the case of the Esplanade Underpass to analyse the formation, usage and dynamics of an informal public space in the context of Singapore, so as to better conceptualise the ideas of publicness and the urban public sphere. The study aims to shed light on the nature of public space that exists on the margins of functional modern planning discourses.

I begin with a review of scholarship relevant to the notion of public space and its definition, and provide an overview of the Singaporean context in which this research is grounded. I then proceed to outline the methodology used in this research, which is a qualitative participatory study of the space. The subsequent sections delve into the various aspects of the Underpass, its users and usage. The conclusion discusses the possible implications of the findings of this research for the study of urban public space.

\section{Defining Public Space}

What makes a space public? Geographer Kurt Iveson $(2011,4)$ defines public space simply as a space that is open to members of the public and contrasts this with private space, which is exclusive and closed off. Public spaces, in this sense, are spaces that allow free access. In the urban context, examples might include streets, plazas, or parks, which are commonly provided and managed by municipal authorities. However, increasingly in cities, open spaces that appear public may be privately owned or may develop as the result of private-public development partnerships. This has complicated the debate on what precisely constitutes public space in cities. Writing on the London context, Koch and Latham $(2011,518)$ assert that a necessary feature of public space is its ability to allow urban inhabitants to engage, interact, and come together around recognized common interests. In its ideal manifestation, public space has the users of the space at the core of its meaning, and social outcomes it makes possible are aligned with processes of collective deliberation among 
people with diverse identities (Iveson 2011; Habermas 1962; Koch and Latham 2011). Public space then should be accessible to all, have diverse users and offer plentiful possibilities for human contact (Németh 2009, 2463).

Contemporary public spaces rarely attain this ideal state of inclusivity, and scholars lament the increasingly exclusionary nature of public space in the contemporary city. Iveson (2011), for example, notes that urban authorities often monitor and regulate "on behalf of a public that they claim is intimidated by begging, threatened by graffiti, menaced by boisterous groups of teenagers." (5). Sociologist David J. Madden (2010, 189) echoes this sentiment, claiming that spaces designated as public are increasingly becoming controlled, restricted and privatized, marked by exclusion and inaccessibility. This exclusion comes in the form of both the privatization of spaces for commercial purposes as well as the increasing control and monitoring of space to exclude elements of the public deemed undesirable. For Madden (2010, 190), public space reflects the wider political context, including the emphasis on social orchestration, surveillance and order. The right to use public space, supposedly the most open, democratic and inclusive element of the city, is foundational to city living. Thus, a draconian control of public space deprives the majority of inhabitants of their right to the city (Lefebvre 2003, 85).

\section{A Space for the Public}

A public space in its ideal sense seems impossible in today's cities, but some question whether it is necessary. Recent scholarship shows that traditional, purposefully designed or designated public spaces are not always the places where the ideals of public space are best realized. The essential features of public space, such as the coming together of differences and the exchange of values and norms, may be found elsewhere. In Putting the Public Back into Public Space, Iveson $(1998,23)$ draws on Iris Marion Young's idea that a "good" public space is one that contains multiple publics. This definition emphasizes that space is composed by actors and activities, rather than any official status or regime of legal access. Young's ideal of public space envisages users engaging with one another and deciding among themselves the norms of usage and interaction. This model of public space minimizes the risk of exclusion and inequality that is often seen in the promotion of a single ideal public (Iveson 1998, 22). Iveson (2007) draws on Young's work when he posits the notion of public space as "any space which is put to use at a given time for collective action and debate." (3). This suggests the possibility of public spaces where members of the public are able to assert their presence and rights despite the increasing restrictions, commercialization or privatization of space.

In his influential book Life Between Buildings, architect and urban designer Jan Gehl (2011) highlights the importance of the spaces "inbetween" and their potential for connecting people and contributing to urban vitality. The ability for people to freely gather and engage in their desired activities in turn attracts others to use such spaces and thus generates vitality (Gehl 2011, 73). Sociologist Jeffrey Hou (2010) argues that while public space is supposed to be "open to all, well-known by all, acknowledged by all," (112) the actual making of public space is subject to the power and control of the state. Through a variety of case studies, Hou documents the ways in which urbandwellers around the world have taken to pockets of forgotten space to carry out their desired activities. Acts of appropriation may differ from city to city, but Hou effectively shows that many cities have what he calls "insurgent public spaces," where new social arrangements are formed (Hou 2010, 12). Similarly, in their book Loose Space, Quentin Stevens and Karen Franck (2006) evoke pockets of space where, in the absence of excessive design, control and monitoring of authorities, there is a strong variety and representation of both actors and activities. These pockets of space and the acts of appropriation that they host thus loosen the tight control that authorities impose upon the urban public sphere. 


\section{Public space in Singapore}

In the context of Singapore, urban space has historically been determined by functional planning principles (Hornidge and Kurfürst 2011, 346-347). Order in society is tied to both the legibility of the built environment and the effective regulation of space (Yeoh 2003, 268; Goh 2005, 75). Land in Singapore is neatly zoned by functions, such as retail, transport, residential, and so on. This quest for order was fitting in the immediate post-independence days of Singapore, given the social disorder and political instability of the new nation (Teo 1992, 171). The need and desire for order thus resulted in heavy social orchestration and paternalistic governance that are characteristic of Singapore's urban development policies (Dale 1999, 98).

The paternalistic nature of governance in Singapore manifests itself clearly in the planning and control of public space. To ensure order in public space, for example, the government implemented Section 141 of the Penal Code, which prohibits assembly of 5 or more persons in the public sphere for the purpose of protesting (Yeo et al 2012, 381). "Legal" protests must be granted prior permission, and are physically limited to the Speaker's Corner of Hong Lim Park (Padawangi $2014,12)$. In this arrangement of order, the void decks of the Housing Development Board (HDB) residential estates are some of the few spaces in Singapore that are not so function-specific and are sanctioned to accommodate public

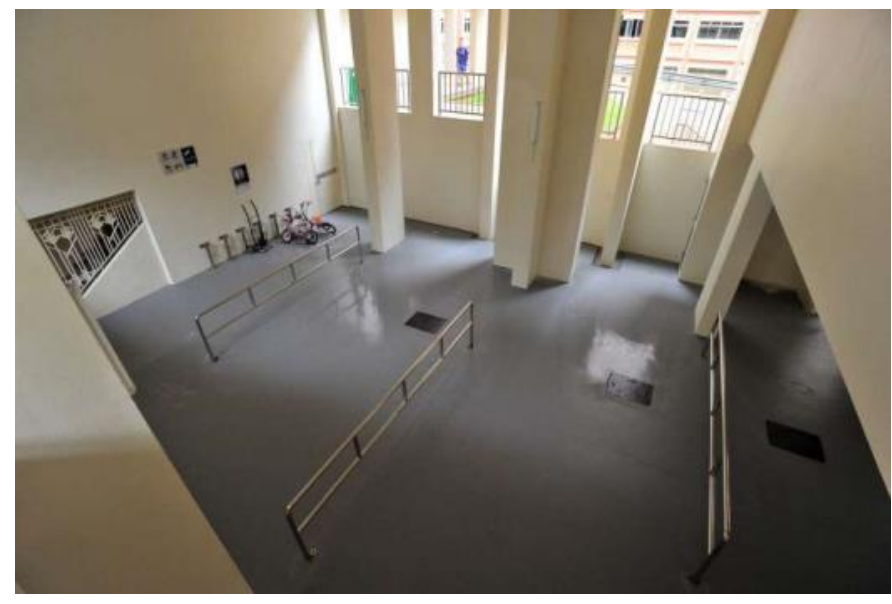

Figure 1. Railings placed at a void deck to deter young boys from playing ball games (Source: Jo, Ong and Chia, 2016) social gatherings. HDB, a government body, develops and manages Singapore's large stock of public housing, which houses approximately $80 \%$ of the country's population. Constructed at the ground level of residential blocks, void decks were originally intended by the HDB as an "undifferentiated, open region, available for appropriation in different ways for different ends by different groups" (Cairns 2014, 81). They are used for a variety of functions, including weddings, funeral wakes, and as polling stations during elections; they include basic amenities such as benches and chess boards, allowing residents to use the space for leisure.

Despite this original intention to not prescribe functions to the void deck, there have nonetheless been attempts to impose order in these spaces via signage and physical installations (Tan 2016). Railings prevent ball games and signs prohibiting a variety of activities are prominently displayed (Figure 1 \& 2). These are preventive measures to offset possible conflicts of interest between the various users.

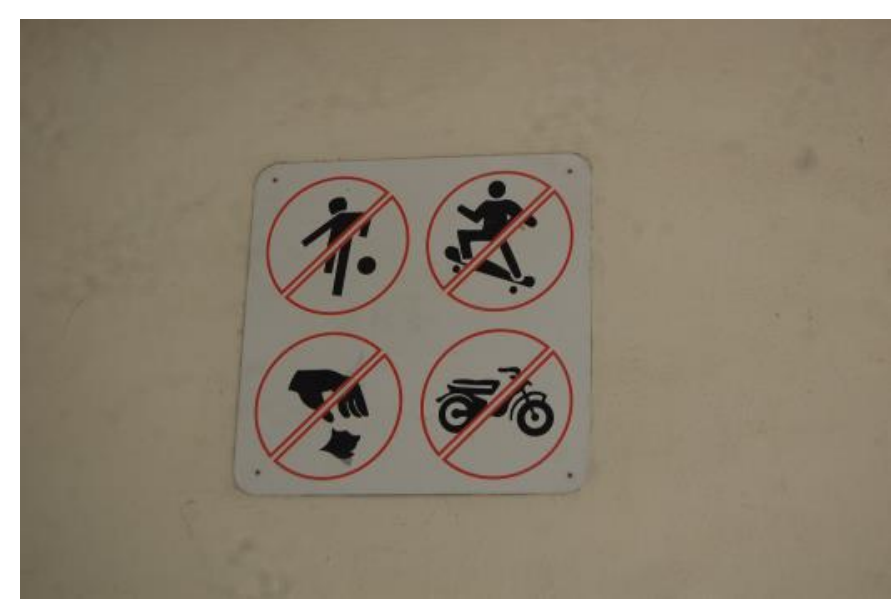

Figure 2. Regulations seen at a void deck in Singapore (Source: Author)

The case of the void deck illustrates the constant intervention of authorities into the regulation of public spaces. In their investigation of public space planning in Singapore, Limin Hee and Giok Ling Ooi (2003, 505) point out that the current practice of planning produces public spaces that are "based on a mere superficial or aesthetic instrumentalization of 'difference'." The vision of public order that the Singaporean state has 
historically pursued thus excludes diverse elements of the public that are considered disruptive to this age-old state narrative (Hee and Ooi 2003, 523).

This research seeks to contribute to the existing scholarship on public space in general and in Singapore specifically by providing a detailed case study of an unconventional space in the Singaporean political context of control and order.

\section{Methodology}

To carry out this study I adopted a mixture of qualitative research methods, including participant observation, semi-structured interviews, as well as photographic documentation. In studying public spaces, sociologist Jan Gehl and Birgitte Svarre (2013) recommend that the public be "observed, their activities and behaviour mapped in order to better understand the needs of users and how city spaces are used" (9). An observational study brings nuanced insight into the social life of the Underpass, as such observations may reveal dimensions that users themselves are not aware of (Gehl and Svarre 2013, 5). Indeed, through prolonged observation of the Underpass, I was able to discern activities that interviewees themselves failed to mention. Observational work was complemented by photographic documentation and activity mapping, which sought to capture individual actions as well as relational social patterns. The key focus of the investigation was the users of the Underpass: their presence and activities, their interactions with others, as well as their interactions with the Underpass built environment. These observations were carried out over 10 sessions on weekdays and weekends, each lasting an average of 3 hours. Observations were undertaken both in the daytime and at night to capture the possible variances in the usage of space. In total, the study draws on 30 hours of observation.

Semi-structured interviews were also carried out with two groups: a sample of users of the Underpass and individuals linked to organizations relevant to the maintenance and governance of the Underpass. Interviews were conducted with a subset sample of users of the
Underpass to understand their experiences in the space, and to access their accounts of why and how they use the space. According to Brinkmann (2014), interviews reveal how the interviewees "experience the world, how they think, act, feel and develop as individuals and in groups" (278). While observations necessarily require the observer to make assumptions and interpretations, interviews allow the subjects to better represent themselves in their own words. Interviews complement direct observations well, as they provide meaningful insights and alternative perspectives into the cursory observations of the researcher Jackson 1983, 40). Eighteen interviews were carried out with a sample of users of the Underpass, with an average length of 20 minutes per interview. The users were selected for their engagement in specific activities which were routine and dominant in the space. In addition, four interviews were carried out with public and private entities relevant to the Underpass so as to gain a better contextual understanding of the creation of the Underpass, and the vision that authorities have for public spaces. These interviews were semi-structured, and the conversation developed based on the responses of the interviewees.

\section{A Closer Look at the Underpass}

With a total area of $1260 \mathrm{~m}^{2}$, the size of the Underpass allows it to accommodate a large number of people. Sandwiched between two large commercial entities, the Esplanade Theatres and CityLink Mall, the Underpass benefits from "leaked" cool air. Thus, despite lacking air-conditioning, the temperature of the space is more comfortable than the tropical heat outdoors. Given its size and ambience, on any night, there could be five or six different groups using the space. A physical feature that complements the size of the Underpass to make it an ideal multifunctional space is its structural columns. There are 20 metal columns in the Underpass, each with a circumference of 2.2 meters. The columns informally act as "territory" markers for the users, and create a public-private nature to the space. While users always return to their "claimed" columns when they take a break from their activities, because these "markers" are impermanent, users still 


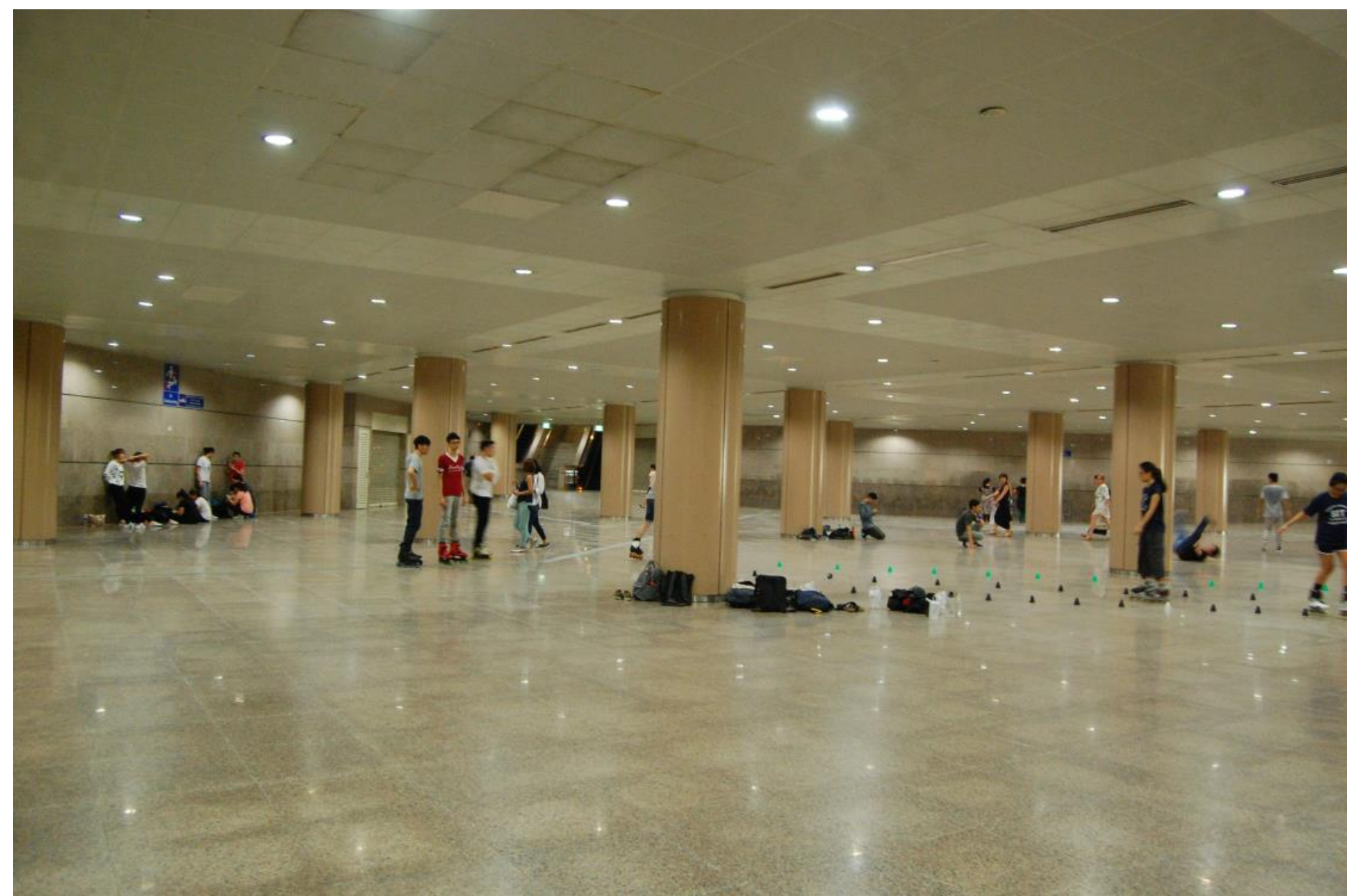

Figure 3. The Esplanade Underpass on a Thursday evening (Source: Author)

adjust and adapt the extent of their territory to accommodate various other users when necessary. This configuration is ideal, as it gives both ownership of the space, and at the same time a sense of mutual responsibility over it to share.

Other features of the Underpass that are adapted in various ways are the floor surfaces and the wall. The tiled flooring of the Underpass is a favorite amongst users. The smooth floor is ideal for skateboarding and stunt cycling. Many dancers prefer the smooth flooring as it allows them to practice more complex moves with limited resistance. While a studio provides the same amenity, a studio is "expensive" and lacks the "rig-and-rag street feel" of the Underpass (Interviewee 9). The tiled walls themselves also have a peculiar use. Unlike a typical dance studio, there are no mirrors at the Underpass. Most dancers thus rely on cameras and hand phones to record their progress, or observe themselves through the minimally reflective surface of the highly- polished, granite finished wall (Figure $4 \& 5$ ). In this way, users creatively make use of the architecture, adapting it to serve their needs.

While the diversity of both users and usage gives the Underpass the semblance of a public space, it is not officially designated as one. It is under the management of Singapore's Land Transport Authority (LTA), and its primary and original purpose is to offer an underground route between the Esplanade Theatres, nearby landmarks, and the underground transport system. The Esplanade Theatres is a key stakeholder as many of its visitors pass through the Underpass. The early appearance of alternative expressive uses of the Underpass led to conversations between the Esplanade Theatres and the LTA (Interviewee 2). It was agreed that the best course of action was to not intervene with the activities at the Underpass, so long as these activities do not hinder pedestrian flow (Interviewee 2). The LTA, the owner of the space itself, tolerates the activities at the Underpass, provided that the Underpass 
is able to maintain its original function as a pedestrian thoroughfare (Interviewee 4). The Esplanade Theatres is aware of the activities that go on at its doorstep; given its status as a cultural and artistic institution of international scale, and its desire to nurture local talents while at the same time maintaining the prestige of its art production, the Theatres made the decision to be a neutral party to allow budding talents a venue to explore their creative side. There was no intention to either stimulate or stifle this "incidental cultivation of spontaneous creativity" (Interviewee 2).

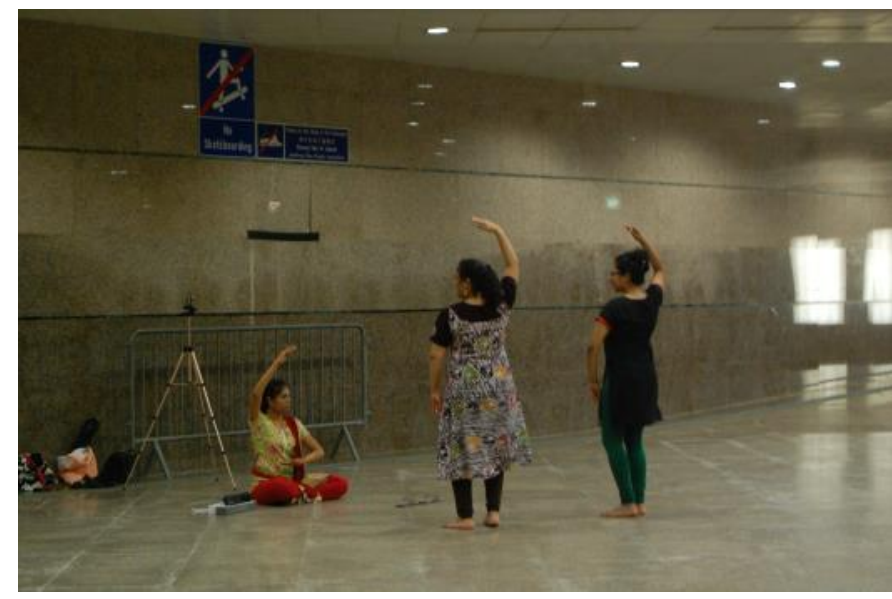

Figure 4. Two dancers using a tripod and their phone to record themselves (Source: Author)

The lack of constant regulation from government authorities and commercial entities further adds to the ability of the Underpass to accommodate varied uses. While public space in Singapore is typically regulated by surveillance cameras, CCTVs are not present at the Underpass. Many of the users interviewed affirmed that they have not seen or been approached by a figure of authority, such as a security guard. This lack of both commercialisation pressure and constant monitoring loosens up the space for "transgressive" behaviours. While there are signs that prohibit sleeping and skateboarding, these activities are constantly taking place at the Underpass.

Although the Underpass is a publicly accessible transit space, it was not designed and built as a public space in any conventional sense. The transformation of the Underpass from a thoroughfare to a public space shows that the meanings and functions of the built environment, if let be, may change over time through the influence of different users. Stewart Brand's book How Buildings Learn (1994) argues that the built environment is not fixed in its meaning and function, but instead is invested with identities dependent on its users and their activities. Similarly, sociologist Tom Gieryn (2002) argues that buildings are "objects of (re)interpretation, narration and representation" (65) and are always experiencing a change of meaning based on users and their ability to reinvent the built environment based on their realization of its alternative possibilities. The Underpass, given its physical characteristics and its lack of surveillance, affords a range of possibilities that often cannot be realized in highly designed and controlled spaces. With its minimal provision of facilities, the Underpass remains versatile in meaning and function. As a space that is "empty of meanings," the Underpass readily "acquire[s] constantly changing meanings - social, political, economic - as users reorganize and reinterpret them" (Chase et al. 1999, 29). Lacking elaborate physical planning and minimal regulation, it is able to accommodate the fluidity of desire and usage, allowing users to design their own experiences.

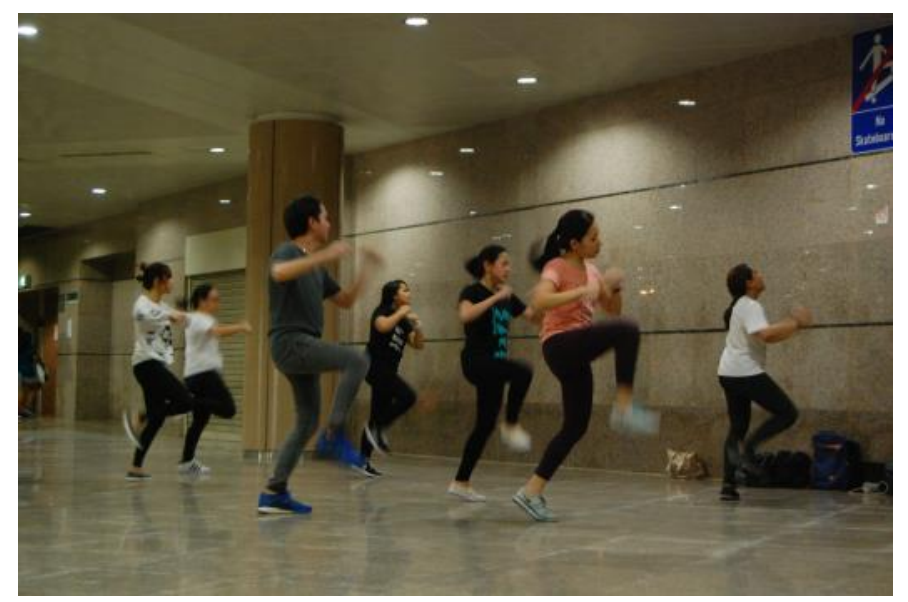

Figure 5. A group dancing facing the wall to catch their reflection (Source: Author)

\section{The Underpass as a Space of Convergence}

Due to its unrestricted nature, the Underpass hosts a variety of users who flow in and out of the space. These users represent a wide range of demographics, and the social characteristics 

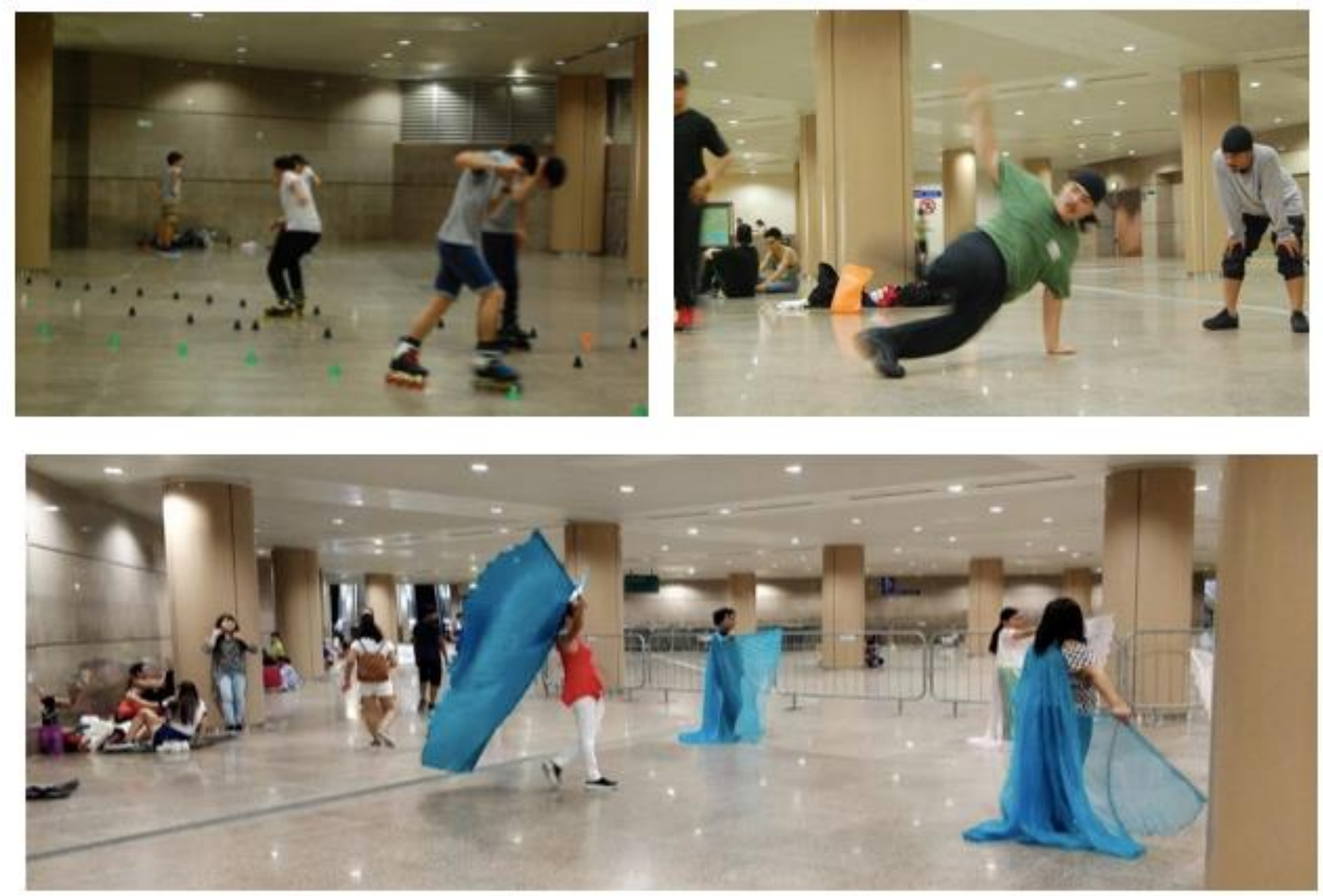

Figure 6. Rollerbladers (top left), break dancers (top right) and domestic workers (bottom) at the Underpass (Source: Author)

of alternative users of the Underpass cut across age, gender, ethnicity and class. Many of the dancers and skaters who come at night are younger adults. While the dancers normally come in gender-exclusive groups, in general both are equally represented. At lunchtime on weekdays, office workers would come to practice a dance routine, or construction workers would come to have their midday rest. On weekends, the space becomes crowded with foreign domestic workers who spend their time catching up or practicing for a showcase, a common event among members of this community. There are also groups that come for weekly exercises, such as zumba or aerobics. Given Singapore's strongly articulated multiracial policy and its status as a global city that attracts immigrants from all around the world, the diversity of Singaporean society is inevitably reflected in the characteristics of the users of the Underpass.
The co-existence of users, whose profiles span across age, gender, ethnicity and class, implies that social relations of the Underpass space are defined not by users' demographic or social differences, but primarily by their activity at the Underpass. At the Underpass, the users were "skateboarders" or "dancers" or "picnickers." This was best exemplified when a female skater said she did not realize she was the only female in the space until it was pointed out to her by the interviewer (Interviewee 18). Social identities and divisions are left outside of the space, generating equality in terms of the right to use the space. This allows the Underpass to truly act as a space of deliberation and inclusion.

A common group of users at the Underpass are the break dancers. The dancers assemble at the Underpass almost as a nightly routine, and they have come a long way on their dance journeys. As one break dancer of the Underpass shared, when he first started 
dancing his secondary school would issue warnings as "breakdancing was seen as bad and dangerous" (Interviewee 8). Having danced at the Underpass for 6 years, this male dancer and his group have found a space where they can practice freely and forge a community where they can learn from other dancers. Here, they also engage in acts that are normally seen as publicly inappropriate, such as dancing shirtless. This is one of the reasons why the dancers prefer the Underpass to governmentsanctioned spaces such as *SCAPE. ${ }^{1}$ The Underpass is thus appealing because it provides a setting for people to comfortably engage in activities that are restricted in other public spaces. In the foyers of private buildings such as the Esplanade Theatres and Changi Airport, dancers are chased out by security (Interviewee 10). In contrast, at the Underpass, users engage in their activities without needing to worry about legality and permissibility. In addition, those who use the space enjoy the accolades of spectators and those passing by (Interviewee 9). This adds to the sense of recognition and legitimation that young users are often denied.

Similarly, skateboarders are a common sight at the Underpass. Scholars, notably Borden (2001), have discussed the ways in which skateboarding is being incorporated into the city through the provision of skate parks, multipurpose recreational youth parks and skate festivals. However, for the most part, skateboarding is restricted to only these designated spaces. Further it is not recognized as a legitimate mode of transport in Singapore. One Underpass skateboarder spoke to this:

At the foyer outside the Esplanade Park, skaters are not allowed. Even though scooters and bikers are allowed, the skateboarders get stopped. It's just a form of transportation for us, but the guards always stop us. (Interviewee 16)

While skate parks are laudable attempts by authorities to make space for skateboarding, the infrastructures provided "do little to replicate the freedom and spontaneity of the sport" (Owens 2002, 158). Another Underpass skateboarder shared his view: "Singapore also has no indoor skate park; and it is hot and rainy so we come here" (Interviewee 15)." The Underpass thus provides skaters with a refuge from the hot and erratic tropical weather of Singapore. According to this skateboarder, attempts to incorporate skateboarding into the urban environment of Singapore do not genuinely address skateboarders' needs, such as the desire for shelter and thermal comfort. At the Underpass, while skateboarding is technically prohibited as communicated through the regulatory signs, the lack of constant enforcement allows skateboarders to practice their craft.

Beyond young people and their various activities, the Underpass also provides shelter from rain and shine for many other groups who are not always given the luxury of space in the public sphere. On weekends, domestic workers make up the majority of the bustling crowd. These are typically Filipinos and Indonesians who live and work with Singaporean households and carry out daily family tasks. On Sunday afternoons, there are at least a dozen groups, with their picnic mats, just catching up with one another. I was told by a Filipino domestic worker that many of them come here to practice dance routines for events, while the Indonesian domestic workers would come to prepare for beauty pageants (Interviewee 19). The two women I spoke with told me that the space was free of distractions, thus allowing them to focus on their activities, reiterating once again the public-private nature of the Underpass. While it gets crowded and rather noisy on Sundays when various groups are engaged in their different activities, for the domestic workers who spend most of their week in the home of their employer, the lively and jovial atmosphere is very much appreciated (Interviewee 20).

As an incidental space, the Underpass acts as an inclusive neutral ground where users engage in activities that are often "unplanned, unscheduled, unorganized and unstructured (Oldenburg 1989, 33)" and from there engage with fellow users of the space. One competitive rollerblader who trains at the Underpass twice a week noted that many of the pioneers in her sport had come here to practice, and this was 
how she got to know others who shared her passion (Interviewee 18). In addition, she made friends with the skateboarders, who "use [her] cones sometimes to practice." These interactions allow her to establish rapport with peers. Another dancer told me that he met his group of friends in informal dancing spots like the Underpass, and they became his mentors halfway through his dance journey. They have been dancing together since 2014, and have expanded their group through the companionship that they have found at the Underpass (Interviewee 9). These stories reinforce the way this space forges communities of interest that cut across other axes of difference.

While these activities and interactions can technically take place in other public spaces in Singapore, they rarely do. Loitering and skateboarding are actively legislated and frequently forbidden. Dancing in public areas, such as on the street, can be seen as disruptive to the orderly and seamless flow of people in transit. The constant regulation of public space reduces its publicness, removing those who do not contribute to the larger construct of order that is at times overemphasised in modern planning principles. By merely being present and active in the space, users contribute to the vibrant multi-publicness of the Underpass.

\section{The Frictions and Seams of Public Interactions}

While peace and order is often deemed as the highest good, in a space that attracts such a diverse public as the Underpass, this singular sense of order is harder to come by. In the words of architect H. Koon Wee (2014, 190), public spaces should "function as receptors designed to absorb and modulate the full range of expressions of the societies they serve, from celebratory events to difficult forms of questioning." This ties back to Iris Marion Young's definition of public space - as a space of contestation and negotiation. A space that is truly inclusive of various actors and their activities cannot avoid occasional conflicts.
At the Underpass, there is an unspoken and assumed hierarchy of use. The dancers associate the space with the Esplanade Theatres, a nationally renowned art institution, and believe that this is the space that the Esplanade Theatres is marking out for them. They thus feel that they have the right of usage over fellow skateboarders and cyclists. This belief is reinforced by signs that prohibit skateboarding. As skateboarding is a fastmoving sport, skateboarders at times run into spatial conflicts with other groups of users. One dancer shared with me about an incident when his group of friends got into an argument with a group of skateboarders who were recklessly doing stunts in the dancers' space (Interviewee 9). This led to a disagreement that quickly became heated, thus requiring a process of difficult negotiation.

Similarly, there is occasional disgruntlement among some dancers and skaters with respect to domestic workers who spend time in the Underpass. Younger users who engage in creative and artistic activities often find it hard to comprehend the choice of those who elect to use the Underpass to lay out their sedentary picnics. They find such actions not a 'productive use' of the space (Interviewee 15). There is an implicit judgement of what is the 'right' and 'wrong' usage of space, causing moments of confusion, discomfort, doubt and confrontation.

When probed further, it became clear that such contentions were not based on judgment of the different users per se, but rather based on actions and behaviors that did not comply with certain assumed protocols or norms. For example, many dancers frowned upon skateboarders who removed the lids off of rubbish bins to use as props, but forget to put them back on the bins (Interviewee 5). Others were unhappy with the litter that some picnickers left behind after their weekly gatherings (Interviewee 10). These minor irritations rarely manifested as outright hostility, but instead resulted in productive cooperation and exchange of values and mutual responsibility. While uncomfortable exchanges may occur, there is no explicit action to curtail other people's usage of the 
Underpass, neither is judgment of other users a common occurrence. In the same anecdote above of the conflict between the dancers and the skateboarders, the dancer reflected that while the official law was on their side because skateboarders were technically not allowed to skate at the Underpass, the last thing he would have done is to resort to contacting the police as a means of resolving the issue (Interviewee 9). There is less concern with the rule of law, but more with common values and a code of conduct, which can be mediated through constructive exchanges.

According to Lefebvre (2003, 180), the dominance of the state over public space and social interaction creates a false understanding and representation of urban society that does not reflect its complexity and diversity. Jane Jacobs (1992 [1961],) echoes this sentiment by calling modern orthodox planning a "dishonest mask of pretended order" (143) through the suppression of organic dynamics and exchanges amongst members of the public. At the Underpass, there is no such mask of order. The adaptive and negotiated social order that exists at the Underpass signifies a space that is truly representative of the heterogeneity of its users, where the public is free to express its diverse nature (Cupers and Miessen 2002, 126). Mutual understanding and shared responsibility are values actively upheld by the users of the Underpass, rather than by any signs of prohibition and penalty, or by an authority of the state. This mutual understanding does not come easily - in fact, it may even come at the cost of occasional confrontations and uncomfortable exchanges. However, through negotiation and compromise, users at the Underpass create an internal code of conduct that upholds unique social norms and values. This will be explored in the final section of this paper.

\section{A Space of Co-creation and Shared Values}

Amidst the many activities at the Underpass is a social order that is arguably essential to the negotiation of conflicts and the peaceful coexistence of its users. The lack of surveillance by an external authority, as well as the limited imposition of the rule of law, requires a code of conduct that the users impose onto one another so as to accommodate the various actors and activities at play. When asked about the conflicts that occur at the Underpass, the majority of users affirmed the mainly peaceful interactions in the space. A skateboarder shared:

This space gets packed with skateboarders on Wednesday nights and on the weekends but there is always space. Skateboarders don't fight over space; we are a very peaceful group. We respect other people's space. We give and take. (Interviewee 17).

Another dancer shared:

Sometimes when we need to film [our dancing], some groups stop their music for us. And when they need to film, we stop our music for them. It's not like we spoke to them or they approached us, but it's because we respect them. (Interviewee 5).

There is tactful yet firm knowledge of how to share space. It is an intentional process, as there is no formal designation of space. The idea of "respect" was often mentioned by interviewees, along with the recognition that users were all facing the same "plight." Everyone needs some space, so everyone gives some space. Everyone needs to film their progress at some point, so users help one another out. This value of respect is not directly communicated between users, but it shapes the interactions at the Underpass to a great extent, as portrayed in these interviews.

In giving respect, users expect respect in return, forging an accountable relationship of "give and take." Mutual understanding amongst users becomes a key reason why the Underpass succeeds in its provision for so many different activities. Users themselves would reinforce the social and spatial order of the space when this mutual understanding is compromised. As much as possible there is an attempt to promote the value of sharing space. The users themselves become a sort of authority, actively making sure that the norms are upheld and respected. 

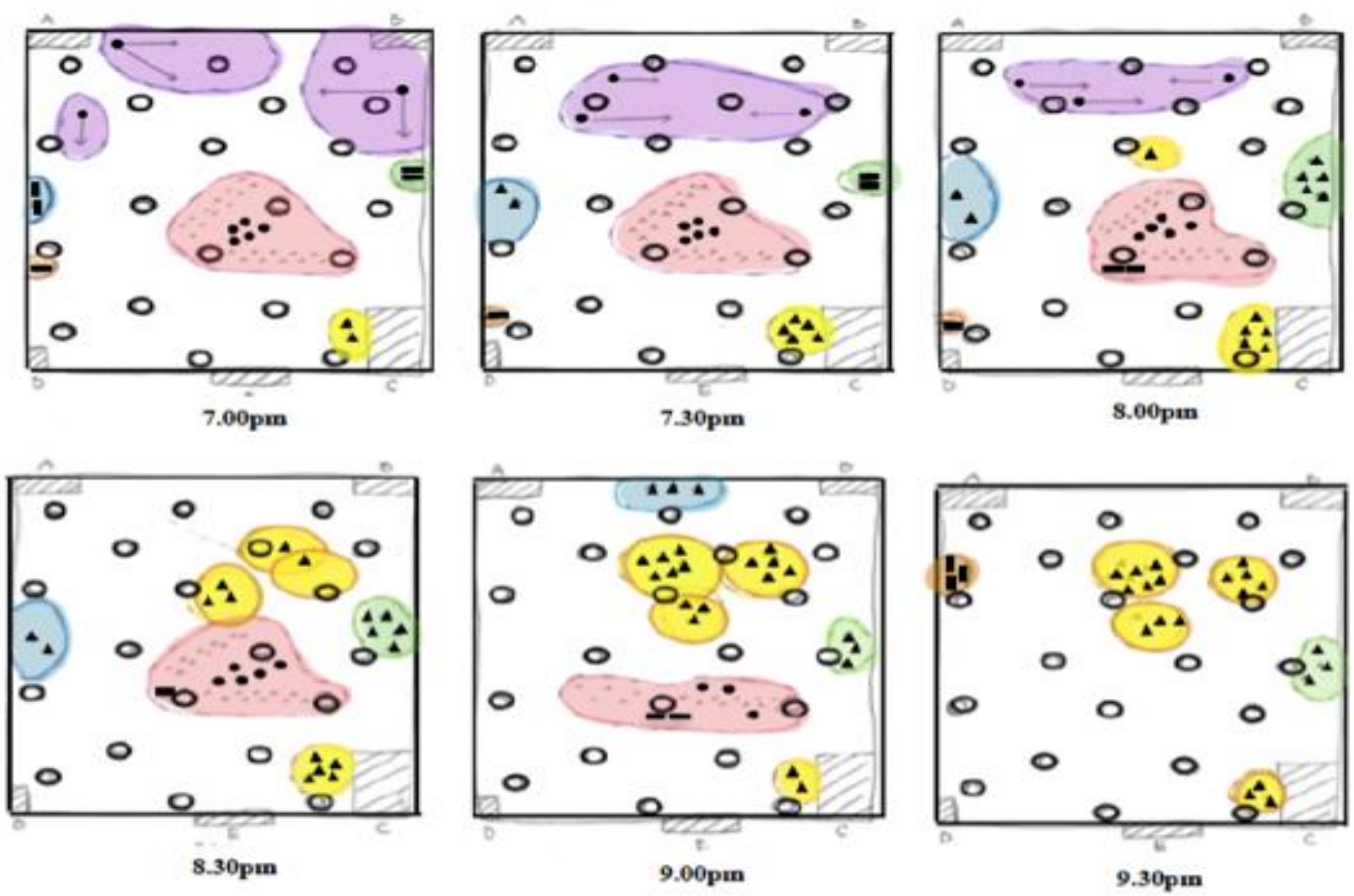

- Skaters
- Dancers
- Stationary activities
Spatial "territory"
OColumns at the Underpass

Figure 7. Diagrammatical representation of the activities at the Underpass in 30-minute intervals, from 7.00pm - 9:30pm, Thursday 09/02/2017. The different colours represent the changing "territorial" boundary of the groups. As seen, these

One dimension of how difference is managed at the Underpass is through a temporal sorting. Middle class office workers dancing at lunch time do not use the space at the same time as the homeless men bedding down for the night, or with the school-aged skateboarders. During early evening, the Underpass is dominated by skateboarders and rollerbladers, and later at night the break dancers arrive. Sunday is when space is shared with domestic workers. Such temporal trends in usage are expected and anticipated. While anyone can come and use the space, there is a general respect for the norms that have naturally emerged from the use of the space over the years.

Figure 7 represents this temporal-spatial delineation of space and the respect shared amongst users in the process of spatial negotiation. The "territory" of the different groups shift to accommodate new users coming in. On a Thursday night, for example, as the Underpass begins to fill up with more users at $8 \mathrm{pm}$, the rollerbladers (red) rearrange their cones to make room for the break dancers. Similarly, as more pedestrian traffic flows in and out of the Underpass from $7 \mathrm{pm}$ to $8 \mathrm{pm}$, the skateboarders (purple) will restrict their movements to where fewer people are passing by, instead of skating across the thoroughfare route.

In place of the standard modes of supervision of CCTV and security personnel, at the Underpass, the only constant "authority" is the cleaner, whose company is contracted by the LTA. The cleaner comes twice a day to clean the Underpass. He knows the people who come here, and when I was conducting my research he pointed to me the good dancers. The cleaner contributes to the life of the space itself, not 
only by "holding the space" together through his work of maintenance, but also through his daily participation in the events of the space (Jacobs et al 2012, 3). The cleaner colludes in the making of the Underpass as a public space that accommodates alternative users and uses. In fact, he plays an important role in maintaining the unofficial status quo of the space. He does not report the skateboarders that he sees using the lids of trash bins as obstacles. When the longboard skaters spread chalk over the underpass floor, the cleaner does not report or scold them. Instead, he hands them a mop and a bucket, and asks them to clean up after themselves in an attempt to teach them to be "responsible" and to "respect other people" (Interviewee 07).

Where there is no existing structure and order, there can be more room for invention, creation and collaboration, thus resulting in users of the space being motivated and empowered to "reinvent culture from scratch" (Hughes and Sadler 2000, 149). This reinvention of culture shows itself in the interactions between the cleaner and his friends, amongst the dancers in the space, thus instrumenting a new social imagination that differs from the social programming of public space imposed by those in power (Holston 2012, 424). At the Underpass, property owners do not chase skateboarders out; security guards do not remove unauthorized objects stored by the public. The nature of the relationships that exist at the Underpass is not one between an authority and the public, nor one between a law-abider and a law-breaker. It is an instructive and constructive relationship between co-users of the same space. All of this brings back the centrality of the public into public space.

\section{Conclusion}

Despite being a space of transit, the Underpass has been transformed into a space that houses a truly vibrant public life made up of a diverse public. The Underpass was never designed with elements of an ideal public space in mind, and yet it is able to realize and fulfil the promise of a public space that is inclusive, representative and fluid in its meanings and norms. It is a space that succeeds in evoking a sense of ownership, empowerment and freedom, thus lending it the appearance of an ideal public space.

In the words of sociologist Henri Lefebvre, the city should be a space where conflicts are openly expressed and where inhabitants gain full participation in different processes and outcomes (Purcell 2008, 94; Lefebvre 2003, 163). At the Underpass, we see the mixing and mingling of different groups who use the space, all of whom engage in a process of negotiating the space amongst one another. We see official regulations being transgressed, as alternative norms of respect and mutual understanding arise. Such spaces as the Underpass allow users to realize rights to the city that are often lost in the bureaucratic production and control of space. If such a space were to be seriously considered and successfully incorporated into the planning of the city, Singapore would have the potential to become a more vibrant and adaptive city, especially in the fast-changing global scene.

In recent months, new developments have occurred in the space that pose an interesting provocation to this study. If before the Underpass was unique in its lack of surveillance and imposition of order, this uniqueness has now eroded as cameras have been installed at the four exits leading out of the space. Advertising boards that were once dilapidated are now renovated and used by the LTA for the announcement of their future development plans. One hypothesis of this paper was that the lack of tight surveillance at the Underpass has allowed for a diverse range of users and activities to flourish, consequently leading to a more representative and dynamic public sphere. This change in policy and control of the space creates a rare opportunity for a beforeand-after study, where it is possible to test for the impact of surveillance and control on the publicness and the use of space. Such work, of which the present study contains many insights of the "before" condition, has the potential to have far-reaching consequence on the future of public space in Singapore. 


\section{Acknowledgements}

I would like to extend my deepest gratitude to the editors of the Journal for Undergraduate Ethnography for all their mentorship and support, and a special thank you to professor Jane Jacobs, who never failed to provide me with patient guidance and thoughtful feedback, pushing me to think harder about my research. Thank you to all the friends and family who were always willing to listen to my random musings, and to all the interviewees who agreed to be a part of this research. It has been such a journey, and I could not have done it without all of you.

\section{Endnotes}

${ }^{1 * S C A P E}$ is a popular government-run space in downtown Singapore that is specifically designated for youth activities. *SCAPE is typically packed with teenagers and is closely monitored by property owners. 


\section{References}

Borden, lain. 2001. Skateboarding, Space and the City: Architecture and the Body. Oxford: Bloomsbury Academic.

Brand, Stewart. 1995. How Buildings Learn: What Happens After They're Built. New York: Penguin Books.

Brinkmann, Svend, Kvale, Steinar. 2014. InterViews: Learning the Craft of Qualitative Research Interviewing, 3rd edition. Los Angeles: SAGE Publications, Inc.

Chase, John, Kaliski, John and Crawford, Margaret. 1999. Everyday Urbanism. New York: The Monacelli Press.

Cupers, Kenny, Miessen, Markus. 2002. Spaces of Uncertainty. Wuppertal: Müller und Busmann.

Dale, Ole Johan. 1999. Urban Planning in Singapore: The Transformation of a City. Oxford: Oxford University Press.

Ethnic Integration Policy and SPR Quota | HDB InfoWEB [WWW Document], n.d. URL http://www.hdb.gov.sg/cs/infoweb/ residential/buying-a-flat/resale/ethnicintegration-policy-and-sprquota (accessed 3.8.17).

Franck, Karen, Stevens, Quentin. 2006. Loose Space: Possibility and Diversity in Urban Life. New York: Routledge.

Gehl, Jan, Svarre, Birgitte. 2013. How to Study Public Life. Washington: Island Press.

Gehl, Jan. 2011. Life Between Buildings: Using Public Space. Washington: Island Press.

Gieryn, Thomas. 2002. "What Buildings Do." Theory and Society 31(1): 35-74.

Goh, Robbie. 2005. Contours of Culture: Space and Social Difference in Singapore. Hong Kong: Hong Kong University Press.

Habermas, Jürgen. 1991. The Structural Transformation of the Public Sphere: An Inquiry into a Category of Bourgeois Society. Massachusetts: MIT press.

Hee, Limin, Ooi, Giok Ling. 2003. “The Politics of Public Space Planning in Singapore." Planning Perspectives 18(1): 79-103.

Hornidge, Anna-Katharina, Kurfürst, Sandra. 2015. “Envisioning the Future. Negotiating Public Space in Hanoi and Singapore." Internationales Asienforum 42(3/4): 345-369. 
Hou, Jeffrey (Ed.). 2010. Insurgent Public Space: Guerrilla Urbanism and the Remaking of Contemporary Cities. New York: Routledge.

Hughes, Jonathon, Sadler, Simon eds. 2007. Non-Plan: Essays on Freedom Participation and Change in Modern Architecture and Urbanism. Oxford: Architectural Press.

Jacobs, Jane, Margaret, Cairns, Stephen, and Strebel, Ignaz. 2012. "Doing Building Work: Methods at the Interface of Geography and Architecture." Geographical Research 50(2): 126-140.

Iveson, Kurt. 1998. "Putting the Public back into Public Space." Urban Policy and Research 16(1): 21-33.

Iveson, Kurt. 2011. Publics and the City. Oxford: John Wiley \& Sons.

Jackson, Peter. 1983. "Principles and Problems of Participant Observation." Geografiska Annaler. Series B, Human Geography 65(1): 39-46.

Jacobs, Jane. 1992. The Death and Life of Great American Cities. New York: Vintage Books.

Jo, Yeo Sam, Ong, Alexis, and Chia, Rachel, 2016. "Void Deck Railings to Stop Ball Games" Straits Times, February 25. Accessed June 1, 2018. https://www.straitstimes.com/singapore/housing/void-deck -railings-to-stop-ball-games

Koch, Regan, and Latham, Alan. 2012. "Rethinking Urban Public Space: Accounts from a Junction in West London." Transactions of the Institute of British Geographers 37(4): 515-529.

Lefebvre, Henri. 2003. The Urban Revolution. Minneapolis: University of Minnesota Press.

Madden, David J. 2010. "Revisiting the End of Public Space: Assembling the Public in an Urban Park." City \& Community 9(2): 187-207.

Németh, Jeremy. 2009. "Defining a Public: The Management of Privately Owned Public Space." Urban Studies 46(11): 2463-2490

Oldenburg, Ray. 1989. The Great Good Place: Café, coffee shops, community centers, beauty parlors, general stores, bars, hangouts, and how they get you through the day. Minnesota: Paragon House Publishers. 
Padawangi, Rita. 2014. "Counter-Hegemonic Spaces of Hope? Constructing the Public City in Jakarta and Singapore." $A R /$ Working Paper Series 219. Asia Research Institute, National University of Singapore.

Purcell, Mark. 2008. Recapturing Democracy: Neoliberalization and the Struggle for Alternative Urban Futures. New York: Routledge.

Yeoh, Brenda S.A. 2003. Contesting Space in Colonial Singapore: Power Relations and the Urban Built Environment. Singapore: Singapore University Press.

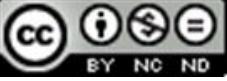

This work is licensed under a Creative Commons

Attribution-NonCommercialNoDerivatives

4.0 International License. 